Témoigner Témoigner. Entre histoire et mémoire

Getuigen Revue pluridisciplinaire de la Fondation Auschwitz

$127 \mid 2018$

Perpétuation de la violence après 1918

\title{
Arnaud de la Croix. "Ils admiraient Hitler. Portraits de 12 disciples du dictateur"
}

Jean-Pierre Pisetta

\section{Q OpenEdition}

1 Journals

Édition électronique

URL : https://journals.openedition.org/temoigner/7916

DOI : $10.4000 /$ temoigner.7916

ISSN : 2506-6390

Éditeur :

Éditions du Centre d'études et de documentation Mémoire d'Auschwitz, Éditions Kimé

Édition imprimée

Date de publication : 1 octobre 2018

Pagination : 124-125

ISBN : 978-2-930953-076

ISSN : 2031-4183

Référence électronique

Jean-Pierre Pisetta, "Arnaud de la Croix. "Ils admiraient Hitler. Portraits de 12 disciples du dictateur" », Témoigner. Entre histoire et mémoire [En ligne], 127 | 2018, mis en ligne le 10 février 2022, consulté le 14 février 2022. URL : http://journals.openedition.org/temoigner/7916 ; DOI : https://doi.org/10.4000/ temoigner.7916

Ce document a été généré automatiquement le 14 février 2022.

Tous droits réservés 


\title{
Arnaud de la Croix. "Ils admiraient Hitler. Portraits de 12 disciples du dictateur"
}

\author{
Jean-Pierre Pisetta
}

\section{RÉFÉRENCE}

Arnaud de la Croix. Ils admiraient Hitler. Portraits de 12 disciples du dictateur, Bruxelles, Racine, 2017, 160 p.

1 «Ils admiraient Hitler. » Combien de millions de personnes l'ont admiré, du moins à ses débuts! Mais Arnaud de la Croix, philosophe et historien, ajuste aussitôt le tir dans son sous-titre en nous annonçant que ce n'est pas de la masse, des foules de ses admirateurs qu'il va nous parler, mais de 12 d'entre eux, triés sur le volet.

2 Le premier, éphémère roi d'Angleterre (il régna moins d'un an en 1936), est peut-être le plus pâle d'entre eux. Il croyait naïvement en l'amitié anglo-allemande et aurait sans doute tout fait pour rapprocher son île du Reich, mais vite écarté des affaires britanniques en raison d'un mariage jugé indigne par la nation, il dut renoncer à œuvrer au destin de son pays et végéta, durant la guerre, dans un poste d'apparat aux Bahamas, non sans avoir pris soin de recommander à ses anciens amis allemands et italiens, nazis et fascistes, de veiller à ce que ses résidences privées de Paris et d'Antibes ne subissent aucune déprédation, souhait que ces deux envahisseurs conjoints de la France se firent un devoir d'exaucer.

3 Leni Riefenstahl, comédienne, danseuse, réalisatrice de films magnifiant les apparitions publiques du Führer ou les idéaux de son régime, films portés au pinacle par des personnalités aussi différentes qu'Hermann Goering ou Mick Jagger, sort miraculeusement blanchie, en 1949, d'une procédure de dénazification. Ses films, des chefs-d'œuvre probablement sur le plan visuel, n'en contribuèrent pas moins à déifier Hitler et à présenter le nazisme comme un élan sublime vers un monde meilleur. Elle 
vécut presque centenaire, continuant, jusqu'à la fin, à prétendre ne s'être vouée qu'à l'art et n'être pour rien dans l'utilisation que les nazis firent de ses productions, y compris celle où, pour les besoins d'un de ses scénarios, elle était allée chercher des figurants tziganes dans un camp de transit, avant de les laisser repartir, une fois le tournage bouclé, vers Auschwitz.

Henry Ford, après avoir asservi l'homme américain par l'invention du travail à la chaîne, asservit également l'homme soviétique - au grand dam et des contempteurs du communisme aux États-Unis et des ennemis du capitalisme en URSS - en construisant la première usine de construction automobile en Russie, à Gorki, dans les années 1930. Hitler s'inspire ensuite de la Ford T, voiture «démocratique » conçue en 1908 par le constructeur américain, pour lancer sa voiture du peuple, la fameuse "Volkswagen ", en 1936. Le 30 juillet 1938, Henry Ford se voit décoré par les représentants du gouvernement allemand en poste aux États-Unis de la «Grand-Croix de l'Ordre de l'Aigle allemand ", décoration créée par le Führer un an plus tôt. L'usine Ford de Poissy, en France, bombardée par les Alliés en 1942, reçoit du gouvernement de Vichy une indemnisation de 30 millions de francs. Si l'on ajoute à cette proximité de ces régimes pour le moins "antidémocratiques ", proximité toujours démentie par Henry Ford, la publication par ce dernier d'un recueil d'articles antisémites sous le titre Le Juif international, livre tellement apprécié par Hitler qu'une photo d'Henry Ford trônait dans son bureau à ses débuts, on comprendra pourquoi Leni Riefenstahl, lors d'un voyage aux États-Unis en 1938, fut accueillie à bras ouverts chez le constructeur à Detroit. Le fait que Charlie Chaplin ait attaqué, dans deux films consécutifs, le système Ford (Les Temps modernes) et le système nazi (Le Dictateur), relevait peut-être de la dénonciation d'un même type d'abrutissement de l'homme par l'homme.

5 En 1936, Charles Lindbergh, as de l'aviation s'il en est, est invité, par l'attaché militaire de l'ambassade américaine à Berlin, à visiter l'Allemagne et à donner un avis sur l'état des forces aériennes du Reich. Après avoir vu la France « en proie à l'instabilité » qu'y répandait, selon lui, le Front populaire, il est ébloui par l'ordre et le dynamisme qu'il voit régner en Allemagne. Accueilli comme un dieu du ciel par l'aviateur Hermann Goering, qui déploie devant ses yeux ébahis toute la puissance aéronautique du régime, Lindbergh quitte le pays après avoir rencontré Hitler. De retour de ce voyage, il cherche à convaincre ses compatriotes, également à travers les écrits de sa femme écrivain, qu'il faut collaborer avec Hitler et son pays modèle. Combattre une telle puissance serait par ailleurs contreproductif, voire suicidaire. L'aveuglement de ce héros des airs, qui avait vaincu l'Atlantique en 1927 en le traversant d'une traite de New York à Paris et n'avait vu du régime hitlérien que le clinquant - peut-être fut-il ébloui par l'éclat de la décoration que lui remit personnellement Goering lors de son deuxième voyage en Allemagne en octobre 1938, la même que celle qu'avait reçue Henry Ford deux mois et demi plus tôt -, cet aveuglement laisse pantois et l'on comprend que l'aviateur ait passé le reste de sa vie (c'est-à-dire une bonne trentaine d'années : il meurt en 1974) à le faire oublier en s'occupant exclusivement, loin de l'Histoire, de la préservation de la nature et des peuples primitifs.

Robert Brasillach est fusillé le 6 février 1945. Sa faute : avoir utilisé sa plume brillante d'écrivain et de journaliste dans des articles collaborationnistes. Son tort : avoir cru que la France tirerait profit de son union avec l'Allemagne alors que cette dernière avait un secret dessein que Brasillach n'avait pas discerné, contrairement à un autre écrivain de son temps, Vercors, qui l'étala au grand jour dans Le Silence de la mer: 
ruiner, anéantir la pensée, l'esprit français. Comme Virgile, un de ses modèles en littérature et en art de vivre, il « aimait les grands vainqueurs qui violent toutes les lois jusqu'au moment où ils en donnent aux autres. » Il aimait Hitler pour cela, même si lors de leur unique rencontre, il fut frappé par la «tristesse de ses yeux». Pendant son procès, en 1945, il se défendit en rappelant « que sa politique avait été dirigée par des principes qui furent les siens avant la guerre et qui se réfèrent à une tradition française qu'on peut rejeter, mais qui est bien antérieure à l'hitlérisme.» De même que l'antisémitisme français, ajouta-t-il : «Drumont, antisémite français, a publié La France juive trois ans avant la naissance d'Hitler. » Force est de reconnaître que, sur ces points, on ne peut que lui donner raison.

7 Parmi tous les autres admirateurs observés par Arnaud de la Croix - le philosophe Martin Heidegger, le Grand Mufti de Jérusalem Amin al-Husseini, le Belge Léon Degrelle, l'écrivain norvégien nobélisé en 1920 Knut Hamsun, le cardinal autrichien Alois Hudal et l'écrivain américain Howard Phillips Lovecraft -, le cas de Benito Mussolini est, tout compte fait, une histoire bien morose. L'inventeur du fascisme, qui tient le haut du pavé en Italie depuis sa marche sur Rome en 1922, est admiré par Hitler jusqu'à sa propre accession au pouvoir en 1933. Puis, peu à peu, les rôles vont s'inverser : le disciple dépassera le maître, malgré une période où ils seront au coude à coude dans le hit-parade des succès guerriers. Après le 25 juillet 1943, jour de la destitution et de l'arrestation du Duce en Italie, ce dernier terminera sa carrière politique comme sous-fifre du Reich et il sera fusillé sans autre forme de procès sur une route de montagne, à la grande satisfaction des fascistes italiens qui, convaincus, à juste titre, que leur chef avait payé pour eux tous, purent, une fois leur chemise noire ôtée, regagner leurs foyers sans jamais être inquiétés.

8 Cette galerie de portraits brossés par Arnaud de la Croix est à la fois fascinante et accablante, car si le parcours de certaines d'entre ces 12 personnalités les conduisait tout naturellement vers le respect de ce "guerrier », comme l'appelait l'écrivain Knut Hamsun, d'autres, parmi lesquels figurent notamment ce prix Nobel de littérature, mais aussi Martin Heidegger ou encore Howard Phillips Lovecraft, auraient dû, par leur don de l'observation qui va généralement de pair avec le génie, être immunisés contre une idéologie aussi primaire. C'est pourquoi il faut lire et faire lire ce livre, afin que l'on sache que personne - pour peu que l'on soit antisémite, caractéristique qui unit les 12 personnalités présentées dans le présent ouvrage - n'est, a priori, à l'abri d'une telle déviation. 